\title{
Understanding the carbon-bio interface: Influence of surface chemistry and buffer composition on the adsorption of phospholipid liposomes at carbon \\ surfaces
}

Joana M. Vasconcelos, ${ }^{1}$ Federico Zen, ${ }^{1}$ M. Daniela Angione, ${ }^{1}$ Ronan J. Cullen, ${ }^{1}$ Maria J. SantosMartinez, $^{2}$ and Paula E. Colavita ${ }^{1 *}$

1. School of Chemistry, Trinity College Dublin, Dublin 2, Ireland.

2. School of Pharmacy and Pharmaceutical Sciences, School of Medicine and Trinity Biomedical Sciences Institute, Trinity College Dublin, Dublin 2, Ireland.

\section{Corresponding Author}

*Email: colavitp@tcd.ie 


\begin{abstract}
Surface active phospholipids are present in fluids of biological relevance and their adsorption may condition and determine the response of carbon and nanocarbon surfaces when they are immersed in physiological media. In this work, the adsorption and assembly of liposomes at carbon interfaces was investigated to understand the effect of surface termination on the extent and mode of assembly of lipid aggregates. Liposomes of natural lipids were prepared from a mixture of phosphatidylcholine (PC) and phosphatidylserine (PS) and their hydrodynamic size and surface zeta potential were studied as a function of $\mathrm{pH}$. Adsorption was investigated at graphitic amorphous carbon surfaces (a-C) and at these surfaces after oxidative treatments (a$\mathrm{C}: \mathrm{O})$. Infrared surface spectroscopy experiments show that PC/PS liposomes adsorb at a-C surfaces exclusively, independently of $\mathrm{pH}$, while no adsorption is observed at a-C:O materials. Nanogravimetry and fluorescence imaging experiments in solution indicate that adsorption at aC occurs as supported intact vesicles. Interestingly, PC/PS adsorption at oxidized surfaces was observed only in the presence of a dication such as $\mathrm{Ca}^{+2}$, a behaviour that was attributed to screening of surface-liposome repulsive electrostatic interactions. Vesicle rupture experiments show that lipids adsorb as monolayers on graphitic surfaces, whereas adsorbate structures correspond to bilayers in the case of oxidized carbons. These results therefore demonstrate a strong dependence of adsorbate structure on both carbon chemistry and buffer composition. These findings have important implications for the design of carbon nanoparticles, carbon electrodes or carbon coatings for applications in biology and medicine.
\end{abstract}

Keywords: amorphous carbon, liposomes, phosphatidylcholine, phosphatidylserine. 


\section{Introduction}

Carbon materials are widely used in biological applications, both in the form of coatings or thin films, or as nanoparticles and nanostructured scaffolds. Carbons often demonstrate excellent performance a notable example being that of pyrolytic carbon coatings, ${ }^{1-2}$ while materials such as diamond-like carbon (DLC), amorphous carbon (a-C) and hydrogen-doped carbon (a-C:H) have been integrated into catheters, stents, joint replacements, sensors and even contact lenses. ${ }^{3-9}$ Nanostructured forms of carbon are also of current interest as materials for biological applications: nanotubes ${ }^{10}$, fullerenes ${ }^{11}$, nanodiamonds ${ }^{12-13}$ and porous carbons ${ }^{14-15}$ have all been investigated as promising candidates for therapeutic and diagnostic purposes. The success of carbon as a biomaterial can partly be attributed to mechanical, frictional and corrosion properties that can meet diverse requirements.$^{5-6,16-17}$ However, the origin of their desirable bioresponse is not yet fully understood, and there is great interest in understanding what role carbon surface chemistry might play in determining its properties as a biomaterial. ${ }^{4,18-25}$

During the early stages after implantation, small biomolecules found in biological fluids and tissues transport fast to the surface and they are believed to condition the physiological response to the implanted solid, thus determining the outcome of more complex phenomena that occur over longer timescales, such as cell adhesion., ${ }^{16-28}$ The most abundant biomolecules found in common fluids (e.g. plasma, serum, synovial fluid, tears) are proteins and lipids; both of these broad families of biomolecules modulate biological processes such as binding interactions, adhesion or enzyme function. ${ }^{1,26-27,29-30}$ Considerable attention has been dedicated by us and others to the study of protein/carbon interactions and to novel methods for promoting or

preventing their adsorption. ${ }^{9,} 31$ However, the literature is comparatively sparse regarding lipid/carbon interactions. Lipids are present in concentrations that are similar to those of proteins 
in serum; for instance, the molar concentration of triglycerides and fatty acids in blood plasma $(0.5-2 \mathrm{mM})$ is typically comparable to that of albumin, one of the most abundant proteins. ${ }^{32-33}$ Early studies by Baier and Dutton ${ }^{34}$ had demonstrated that significant amounts of lipids coadsorb with proteins at early times after a material comes into contact with blood. More recent work has also revealed that lipid/surface interactions are critical in determining biomaterial performance and the importance of including lipids in investigations of material bioresponses has been emphasized by several reserchers. ${ }^{1,35-36}$

Lipids in solution are mostly transported as part of aggregates, whether self-assembled into layer structures or as lipoprotein aggregates. Glycerophospholipids, also referred to as phospholipids, are an important subclass of lipids that play a role as structural components in membranes ${ }^{37-38}$ and in aggregates for the transport of other lipids such as triacylglycerols. ${ }^{39-40}$ Besides their functional role in biological membranes, phospholipids also act as boundary lubricant molecules in natural synovial joints. ${ }^{41}$ Surface active phospholipids (SAPL) are present in synovial fluids as aggregates, which consist of almost 50\% phosphatidylcholine (PC) in addition with small \% of other phospholipids, such as phosphatidylserine (PS) and phosphatidylethanolamine (PE). ${ }^{42}$ SAPLs are known to act as an efficient boundary lubrication system which remarkably decreases friction and wear corrosion associated with natural cartilage degeneration, such as osteoarthritis. ${ }^{41,}{ }^{43-44}$ Moreover, synthetic vascular prostheses have shown the formation of atherosclerotic plaques at the bioimplant walls, a process which has been attributed to lipid adsorption at the interface. ${ }^{45}$

One of the simplest models of lipid aggregates is a PC/PS liposome, which consists of a vesicle containing a water core enclosed by at least one PC/PS bilayer. ${ }^{46-47}$ McConnell et al.$^{48}$ were the first to study the interaction between liposomes in suspension with solid surfaces; since then, 
many groups have studied liposome/surface interactions with applications in biosensors, cellsignalling and as a platform for protein studies. ${ }^{49-54} 55$ Liposomes have also been used to mimic the plasma membrane in vitro. ${ }^{47,}{ }^{56}$ However, there is limited information on phospholipid adsorption at carbon coatings, ${ }^{45}, 50,57-60$ and no information is available on the mode of adsorption and its relation to carbon surface chemistry. This work aims at investigating carbon/lipid interactions to better understand: what chemical properties lead to liposome rupture at carbon surfaces, what role surface properties play in determining the mode of liposome adsorption, and whether carbon surface modifications can be leveraged to promote/prevent liposome adsorption.

Herein we investigate the influence of carbon surface termination on PC/PS liposome adsorption: adsorption was studied at a highly graphitic amorphous carbon surface (a-C) and at the same surface after an oxidative treatment. Oxidative treatments are widely used as a method to change the wetting properties and dispersibility of carbon materials ${ }^{61-63}$ and biomaterials, ${ }^{64-66}$ and as a starting point for further functionalization via cross-linking reactions. Using a combination of surface spectroscopy, quartz crystal microbalance with dissipation technology, fluorescence imaging and atomic force microscopy we investigated the effect that $\mathrm{pH}$ and ionic composition have on the amount and mode of adsorption on these two carbon surfaces. Results demonstrate that adsorption and adsorbate structure of zwitterionic/anionic liposomes onto carbon surfaces is highly dependent on both carbon chemistry and buffer composition. Our findings have important implications for the design of carbon nanoparticles, carbon electrodes or carbon coatings for applications in biology and medicine. 


\section{Experimental methods}

Materials and Compounds. Phosphatidylcholine from egg yolk 99.9\% (PC) and 3-snPhosphatidyl-L-serine from bovine brain 95\% (PS) lyophilized powders, phosphate buffer saline (PBS 0.01 M, 0.0027 M KCl and $0.137 \mathrm{M} \mathrm{NaCl} \mathrm{pH} \mathrm{7.4)} \mathrm{tablets,} \mathrm{sulfuric} \mathrm{acid} \mathrm{(95-97 \% ),}$ hydrogen peroxide (30\%), methanol (semiconductor grade), chloroform (HPLC grade) and calcium chloride were purchased from Sigma Aldrich. Texas Red 1,2-Dihexadecanoyl-snGlycero-3-Phosphoethanolamine, Triethylammonium Salt (Texas Red DHPE, ex/em 595/615 $\mathrm{nm}$ ) was purchased from Life Technologies as a lyophilized powder. All water was obtained from a Millipore purification system.

Liposome Preparation. Liposomes were prepared according to previously published protocols. ${ }^{67-69}$ Briefly, stock solutions of $10 \mathrm{mg} \mathrm{mL}^{-1}$ of PC and PS in chloroform were prepared and stored in the freezer; $2.6 \mu \mathrm{mol}$ in 80:20 PC/PS molar ratio were dispensed in a glass vial and dried under Ar and vacuum until dry. $2.6 \mathrm{~mL}$ of buffer were added to the mixture and vortexed until a milky suspension was obtained, which was further sonicated for 30 min until the liquid appeared clear, thus yielding a $1.0 \mathrm{mM}\left(0.79 \mathrm{mg} \mathrm{mL}^{-1}\right)$ suspension in buffer. PC/PS suspensions at varying $\mathrm{pH}$ were prepared using the above procedure, with additions from buffer solutions that were pre-adjusted at $\mathrm{pH}$ values over the range 4.5-9.5. Liposomes were extruded through 0.45 $\mu \mathrm{m}$ and $0.10 \mu \mathrm{m}$ nylon membranes, unless otherwise noted; the filtrate was stored at $4{ }^{\circ} \mathrm{C}$ prior to use. For all fluorescence measurements, $0.02 \%$ by mol of Texas Red DHPE was added to the 1.0 $\mathrm{mM}$ liposome suspension.

Substrate Preparation. A DC-magnetron sputtering chamber (Torr International, Inc.) was used to deposit amorphous carbon (a-C) films at a base pressure $\leq 2 \times 10^{-6}$ mbar and a deposition $\mathrm{Ar}$ pressure of $7 \times 10^{-3}$ mbar, as previously described. ${ }^{70}$ For infrared reflectance absorbance 
spectroscopy (IRRAS), Si substrates were coated with an optically thick $449 \pm 29$ nm (C.I. 95\%) Ti layer via DC magnetron sputtering prior to a-C deposition. Oxidized carbon films (a-C:O) were prepared via exposure of a-C to a UV grid-lamp (UVP, $5.9 \mathrm{~mW} \mathrm{~cm}^{-2}$ of $254 \mathrm{~nm}$ emission at sample distance) in air, as previously described..$^{71-72}$ Patterned oxidation was obtained using a stainless steel shadow mask (courtesy of Prof. Duesberg) with $80 \mu \mathrm{m}$ diameter holes in a square array. The mask was placed in contact with a-C surfaces resulting in a pattern of circular regions of a-C:O on a-C.

Adsorption Experiments. Substrates were rinsed with methanol, dried under Ar and immediately afterwards immersed in $1.0 \mathrm{mM}$ PC/PS suspensions for $1 \mathrm{~h}$, following published protocols. ${ }^{50,60}$ Substrates were rinsed and dried in Ar prior to characterization. For atomic force microscopy (AFM) measurements, $20 \mu \mathrm{L}$ of the PC/PS suspensions were dispensed over surfaces, left for $1 \mathrm{~h}$ in a humid chamber, then rinsed and dried prior to imaging. $1.0 \mathrm{mM}$ liposome suspensions were used for adsorption experiments, except for nanogravimetric measurements in solution, in which case a $0.12 \mathrm{mM}\left(0.10 \mathrm{mg} \mathrm{mL}^{-1}\right)$ concentration of PC/PS in PBS was used.

Characterization Methods. Dynamic light scattering (DLS) and $\zeta$-potential measurements were carried out using a Malvern Zetasizer Nano-ZS, $\lambda=633 \mathrm{~nm}$ He-Ne laser. The signal was detected at $173^{\circ}$ and $13^{\circ}$ for DLS and $\zeta$-potential measurements, respectively. $\zeta$-potential determinations were carried out at $1.80 \pm 0.15 \mathrm{mM}$ total ionic strength, which ensured optimal solution conductivity while avoiding liposome damage; DLS determinations were all obtained at $164 \mathrm{mM}$ ionic strength. X-ray photoelectron spectroscopy (XPS) was performed using an Omicron system $\left(1 \times 10^{-10}\right.$ mbar base pressure $)$ equipped with a monochromated $\mathrm{Al} \mathrm{K \alpha}$ source $(1486.6 \mathrm{eV})$ and a multichannel array detector; spectra were recorded at $45^{\circ}$ take-off angle. 
Peaks were fitted after Shirley background correction using Casa XPS software; atomic ratios were obtained from area ratios using relative sensitivity factors $(C=1.00 ; \mathrm{O}=2.93)$. IRRAS spectra were collected on a Fourier Transform Infrared (FTIR) spectrometer (Tensor 27, Bruker) equipped with a Mercury Cadmium Telluride (MCT) detector, a Zinc Selenide polarizer and a specular reflectance accessory (VeeMax II). 256 spectra were collected at $4 \mathrm{~cm}^{-1}$ resolution at $80^{\circ}$ incidence, with p-polarized light, using a background substrate as noted in each case in the main text; spectra were baseline corrected using FTIR software (WinFIRST). Fluorescence images were obtained with an Olympus BX51 upright microscope, using a DP73 camera and a CoolLed light source; the filter set consisted of excitation bandpass at 530-550 nm, dichroic mirror at $570 \mathrm{~nm}$ and emission filter at 573-648 $\mathrm{nm}$. Fluorescence recovery after photobleaching (FRAP) measurements were performed on a confocal microscope (Leica SP8) equipped with a $\mathrm{Kr} / \mathrm{Ar}$ laser (exc. $552 \mathrm{~nm}$ ). Samples were incubated in suspensions of fluorescently labelled liposomes, then rinsed with water and imaged while wet before, during and after photobleaching, following published protocols. ${ }^{73}$ A $25 \times 25 \mu \mathrm{m}^{2}$ area was photobleached for $10 \mathrm{~s}$, three times, with the high-powered focused laser beam; then, $250 \times 250 \mu \mathrm{m}^{2}$ images were obtained every minute at low-power excitation to monitor recovery. Only brightness and contrast were adjusted in all images presented. Atomic force microscopy (AFM, Asylum Research) was performed in tapping mode $(1 \mathrm{~Hz})$ using Au-coated silicon cantilevers (NT-MDT, 1.45-15.1 N m${ }^{-1}$ spring constant). Images were corrected for background prior to height profile analysis (Gwyddion); thickness determinations were obtained by fitting a step edge to the height profiles extracted along the scan direction (X-axis). Quartz crystal microbalance with dissipation (QCM-D, Q-Sense E4) experiments were carried out using $5 \mathrm{MHz}$ Au sensors coated with $10 \mathrm{~nm}$ a-C films; studies on 
oxidized surfaces were performed on a-C coated sensors exposed for 5 min to the UV lamp. All measurements were carried out at $150 \mu \mathrm{L} \min ^{-1}$ with the sensor module thermostated at $20{ }^{\circ} \mathrm{C} .{ }^{51}$

\section{Results}

Carbon surface characterization. Carbon films were deposited via magnetron sputtering as described in previous work, ${ }^{70}$ and their characterisation has been previously reported in work from our group. ${ }^{72}$ Briefly, amorphous carbon (a-C) surfaces with approximately $80 \%$ trigonally bonded carbon ( $\mathrm{sp}^{2}$ content), as determined via both XPS and Raman characterisation, and approximately $7-9 \% \mathrm{O} / \mathrm{C}$ atomic ratio were obtained. ${ }^{70}$ The material possesses a real refractive index of 1.93 at $633 \mathrm{~nm}$ and a $0.85 \mathrm{eV}$ Tauc gap; ${ }^{31,72}$ its water contact angle and surface free energy had been reported to be $35^{\circ}$ and $63.7 \mathrm{~mJ} \mathrm{~m}^{-2}$, respectively (Supporting Information)..$^{31}$

Exposure of this a-C material to a UV lamp in air, ${ }^{72}$ yields oxidised carbon surfaces (a-C:O), whose main properties are summarised and compared to those of a-C in Table 1. Figure 1a shows survey XPS spectra of the carbon surface before and after the oxidation process, clearly showing an increase in the O1s : C1s peak ratio. Previously reported studies ${ }^{72}$ indicated that the $\mathrm{O} / \mathrm{C}$ atomic ratio increases to $20 \%$ and the $\mathrm{C} 1 \mathrm{~s}$ spectrum displays evidence of carboxylic acid groups (Supporting Information). Oxidation results in higher hydrophilicity as evidenced by a water contact angle below $5^{\circ}$ and in a more negative $\zeta$-potential, which decreases from $-51 \pm 2$ $\mathrm{mV}$ for a-C, to $-62 \pm 4 \mathrm{mV}$ for a-C:O $(\mathrm{pH}=7.4 ; 1.8 \pm 0.15 \mathrm{mM}$ ionic strength). The isoelectric point decreases from $\mathrm{pH}_{\mathrm{iso}}=3.0$ in a-C to $\mathrm{pH}_{\mathrm{iso}}<1.5$ in a-C:O, which is supportive of a higher

density of acid groups. ${ }^{15,72,74}$ Further spectroscopic evidence of the presence of ionisable acid groups was obtained via IRRAS. Figure $1 \mathrm{~b}$ shows spectra of a-C:O immediately after oxidation ratioed against a pristine a-C background (top spectrum), and of the same sample after exposure 
to $\mathrm{PBS}$ solution at $\mathrm{pH}=7.4$, ratioed against its spectrum immediately after oxidation (bottom spectrum). The top spectrum shows a characteristic broad absorbance associated with $\mathrm{C}=\mathrm{O}$ stretching modes of oxidised groups $\left(\sim 1760 \mathrm{~cm}^{-1}\right)$, which likely includes contributions from ketones, carboxylic acids and anhydrides. ${ }^{75}$ After immersion of the a-C:O sample in PBS the difference spectrum (bottom) shows an enhancement of peaks at 1630 and $1385 \mathrm{~cm}^{-1}$ that can be assigned to the asymmetric and symmetric $\mathrm{C}-\mathrm{O}$ stretching modes, respectively, of deprotonated $-\mathrm{COO}^{-}$groups, ${ }^{75-76}$ which are expected to increase in intensity upon exposure to solution at $\mathrm{pH}$ $>\mathrm{pK}_{\mathrm{COOH}}$.
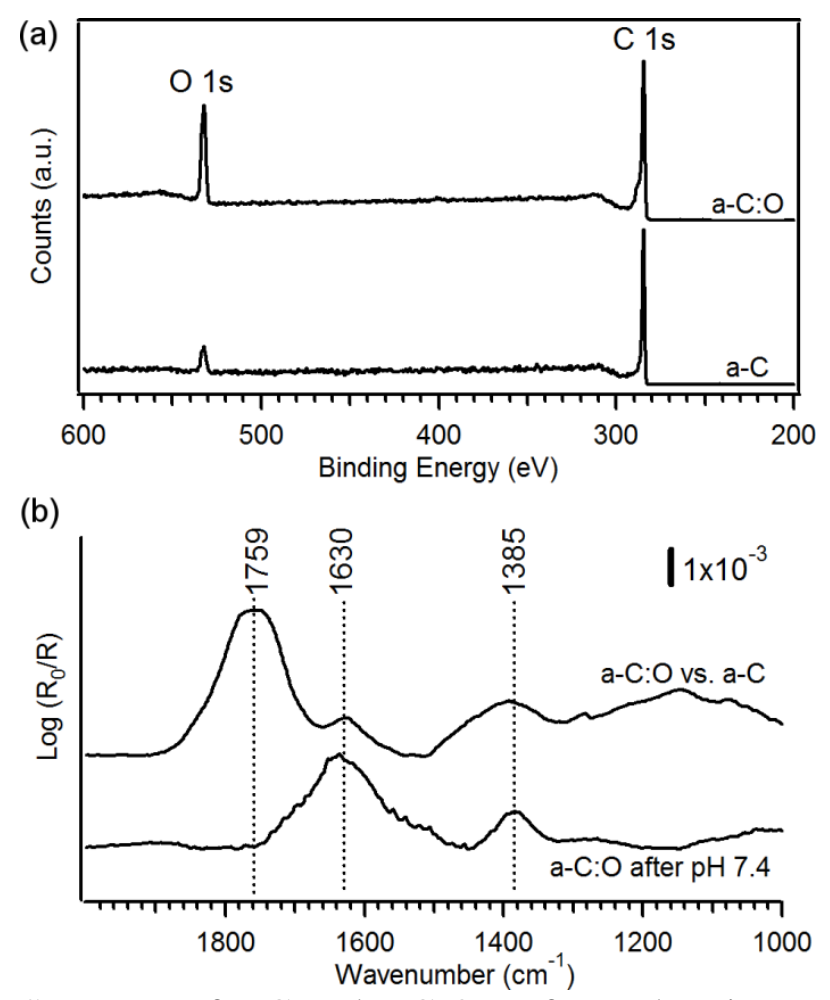

Figure 1. (a) Survey XPS spectra of a-C and a-C:O surfaces showing a direct comparison of the oxygen content. (b) IRRAS spectra of a-C:O ratioed against a non-oxidised a-C background (top), and after exposure to PBS solution at $\mathrm{pH} 7.4$ and ratioed against the top spectrum; spectra are baseline corrected and offset for clarity. 
Table 1 - Summary of composition and properties of carbon surfaces used in our studies based on ref.; ${ }^{72}$ electrokinetic determinations are reported for $1.80 \pm 0.15 \mathrm{mM}$ ionic strength.

\begin{tabular}{cccccc}
\hline & $\begin{array}{c}\text { O/C } \\
\text { at.\% }\end{array}$ & $\begin{array}{c}\text { CAH2O } \\
\left({ }^{\circ}\right)\end{array}$ & $\begin{array}{c}\text { SFE } \\
\left(\mathbf{m J ~ m}^{-2}\right)\end{array}$ & $\begin{array}{c}\zeta \text {-potential } \\
\mathbf{p H ~ 7 . 4 ~}(\mathbf{m V})\end{array}$ & pHiso \\
\hline a-C & 9 & $35.2 \pm 1.4$ & 63.7 & $-51.3 \pm 2.4$ & 3.0 \\
\hline a-C:O & 20 & $<5$ & 63.9 & $-61.5 \pm 3.6$ & $<1.5$ \\
\hline
\end{tabular}

Liposome Adsorption Studies. Figure 2a shows the hydrodynamic diameter of PC/PS liposomes over the 4.5-9.5 $\mathrm{pH}$ range (bars) and their corresponding polydispersity index (PDIdots). The diameter of the liposomes reaches a minimum of $76 \pm 1 \mathrm{~nm}$ at $\mathrm{pH} 8.5$, and increases up to $108 \pm 2 \mathrm{~nm}$ and $241 \pm 2 \mathrm{~nm}$ for basic $(\mathrm{pH} 9.5)$ and acidic ( $\mathrm{pH} 4.5) \mathrm{pH}$ values, respectively. For all sizes, the liposome PDI remained within the range of 0.22-0.39, typically observed for liposomes containing natural phospholipids. ${ }^{77-81}$ Finally, $\zeta$-potential of the liposomes (triangles) at total $1.80 \mathrm{mM}$ ionic strength, remained constant over the $\mathrm{pH}$ range explored at an average value of $-85.1 \pm 0.9 \mathrm{mV}$, as shown in the top plot of Figure $2 \mathrm{a}$, thus indicating that PC/PS liposome suspensions are stable. The relatively constant and negative values of $\zeta$-potential observed across the $\mathrm{pH}$ range explored are consistent with previous determinations of the intrinsic $\mathrm{pK}_{\mathrm{a}}$ values of 0.8 and 3.6 obtained for $\mathrm{PC}^{82}$ and $\mathrm{PS} / \mathrm{PC}^{83}$ layers, as well as with $\zeta$ potential determinations of PS liquid crystals under comparable ionic strength conditions. ${ }^{84}$ $\mathrm{a}-\mathrm{C}$ and $\mathrm{a}-\mathrm{C}: \mathrm{O}$ surfaces were incubated in phosphate buffered liposome suspensions for $1 \mathrm{~h}$, rinsed in water, dried and subsequently analysed by IRRAS. Phospholipid adsorption onto solids yields characteristic peaks of alkyl chains and phosphate groups which are present in the hydrophobic tails and head groups, respectively. ${ }^{85-88}$ Figure $2 \mathrm{~b}$ shows IRRAS spectra obtained for a-C (left) and a-C:O (right) surfaces in the $\mathrm{C}-\mathrm{H}$ stretching region after immersion in suspensions over the 4.5-9.5 $\mathrm{pH}$ range; all spectra are ratioed against a pristine a-C background. 
Peaks at $2924 \mathrm{~cm}^{-1}$ and $2853 \mathrm{~cm}^{-1}$ are assigned to $-\mathrm{CH}_{2}$ antisymmetric and symmetric stretching modes, while the shoulder at $2965 \mathrm{~cm}^{-1}$ is assigned to $-\mathrm{CH}_{3}$ stretching modes. ${ }^{56,89}$ IRRAS spectra of a-C surfaces display strong absorbances associated to the phospholipid alkyl tails at all $\mathrm{pH}$ values examined, however in the case of a-C:O it was not possible to detect any peaks, independently of $\mathrm{pH}$. At lower wavenumbers it is also possible to observe $\mathrm{C}=\mathrm{O}$ stretching peaks at $1736 \mathrm{~cm}^{-1}$ on a-C surfaces, assigned to ester groups in the lipid head groups (Supporting Information); ${ }^{49,89-90}$ however, this region overlaps with $\mathrm{C}=\mathrm{O}$ absorbances of a-C:O, thus making this region of limited use for monitoring lipid adsorption in the case of oxidised carbons. In summary, these results indicate that irreversible adsorption readily takes place at a-C surfaces while no adsorption was detected after oxidation. 
(a)

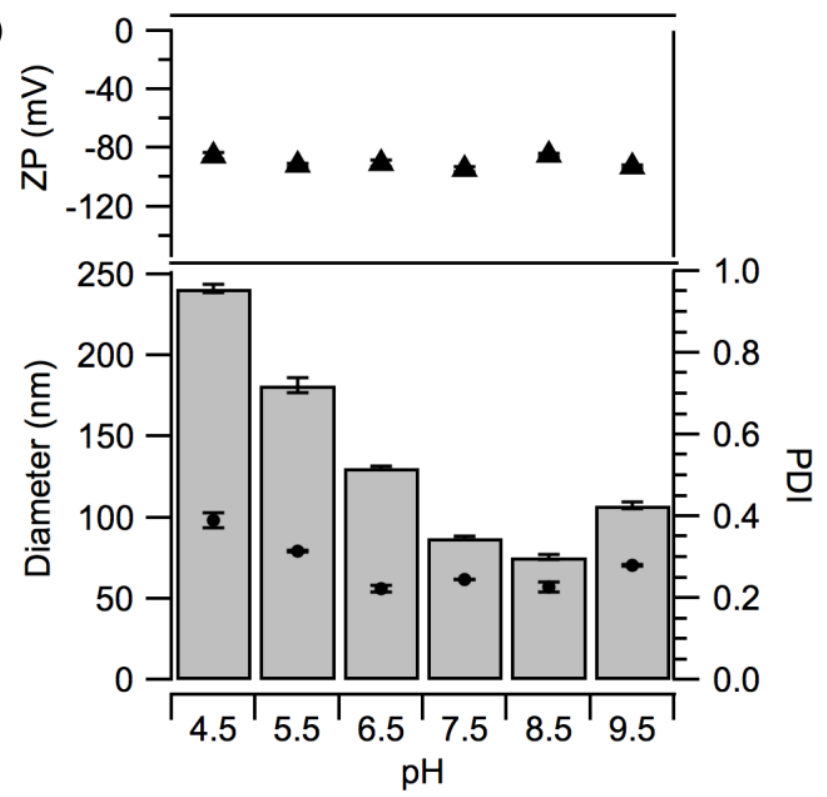

(b)

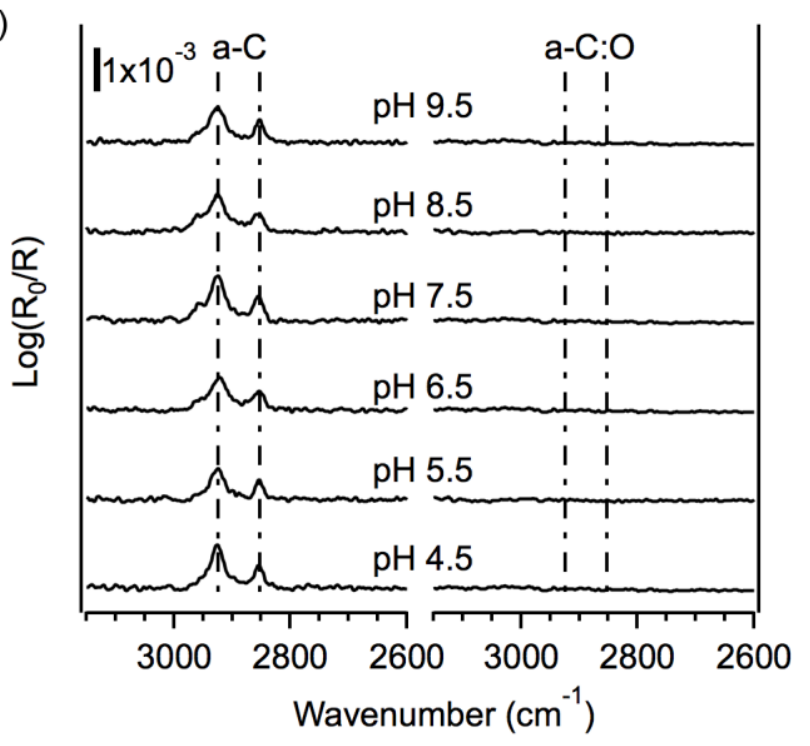

Figure 2. (a) Hydrodynamic diameter of PC/PS liposomes vs. $\mathrm{pH}$ (bars) and corresponding polydispersity index (PDI, dots) obtained via DLS at $164 \mathrm{mM}$ ionic strength; the top plot shows $\zeta$-potential values (ZP) of PC/PS liposomes at $1.8 \mathrm{mM}$ constant ionic strength as a function of pH. (b) IRRAS spectra in the $3150-2600 \mathrm{~cm}^{-1}$ region of a-C (left) and a-C:O (right) surfaces after $1 \mathrm{~h}$ incubation of liposomes suspended in PBS buffer over the 4.5-9.5 $\mathrm{pH}$ range. The position of $-\mathrm{CH}_{2}$ stretching bands is indicated with dotted lines. 

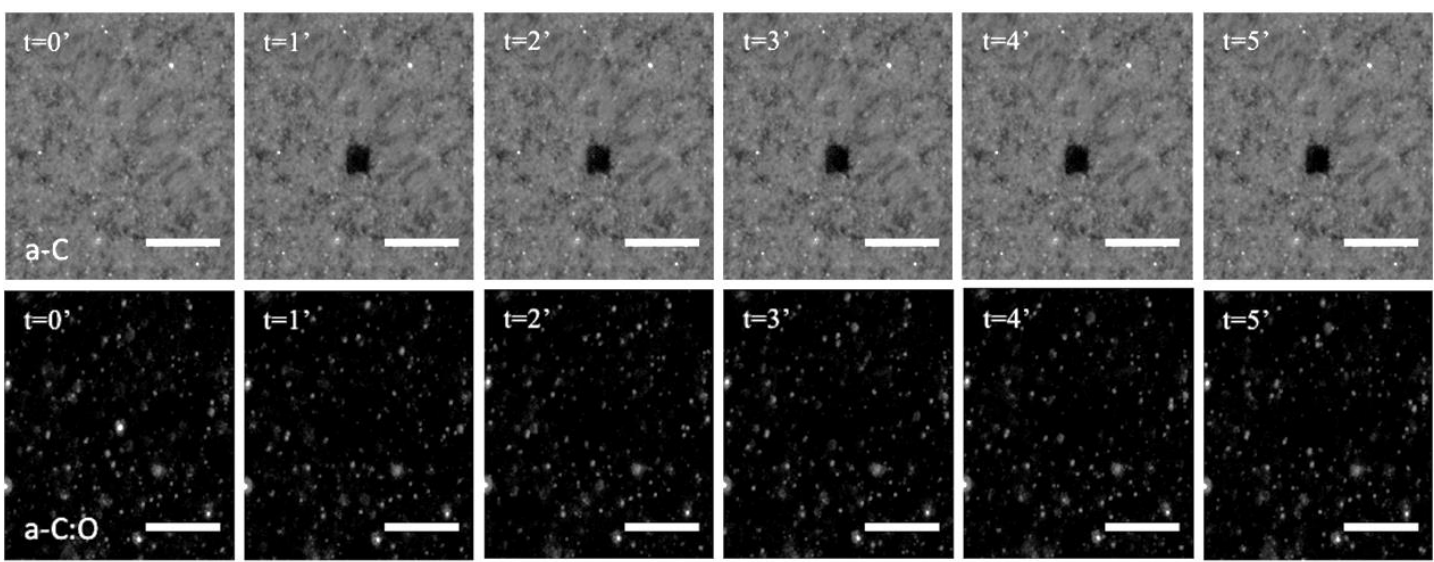

Figure 3. FRAP images obtained after incubation of PC/PS liposomes onto a-C (top) and a-C:O (bottom) surfaces. Each image is $250 \mu \mathrm{m} \times 250 \mu \mathrm{m}$ and the photobleached area is $25 \mu \mathrm{m} \times 25$ $\mu \mathrm{m}$. After photobleaching at $\mathrm{t}=0$ ', images are taken at one minute time intervals. (scale bar corresponds to $100 \mu \mathrm{m})$.

To understand whether differences observed in Figure $2 b$ are only observed when samples are analysed in air, and to determine the mode of adsorption of PC/PS liposomes at carbon surfaces, FRAP experiments were carried out. Surfaces were incubated at pH 7.4 in PC/PS suspensions prepared with Texas Red DHPE, a phospholipid with a fluorescently labelled head group, then rinsed in water and measured while wet. Figure 3 shows fluorescence images collected before $(\mathrm{t}$ $=0 \mathrm{~min})$, during $(\mathrm{t}=1 \mathrm{~min})$ and after photobleaching of the adsorbed lipids. A comparison of the two surfaces in the pre-bleached images shows a much higher emission for a-C compared with a$\mathrm{C}: \mathrm{O}$, thus indicating higher lipid adsorption at a-C vs. a-C:O and in agreement with IRRAS results (Figure 2b). The effect of photobleaching is evident in the case of $\mathrm{a}-\mathrm{C}(\mathrm{t}=1 \mathrm{~min})$, however $<5 \%$ recovery was observed over $4 \mathrm{~min}$ (Supporting Information). This suggests that liposomes are present in the form of intact vesicles at the graphitic carbon surface, as near complete fluorescence recovery would be expected in the case of supported lipid layer formed via vesicle rupture. ${ }^{69,73}$ In the case of a-C:O, no photobleaching was observed as expected based on the absence of lipid adsorption evident from pre-bleaching images and IRRAS results. 


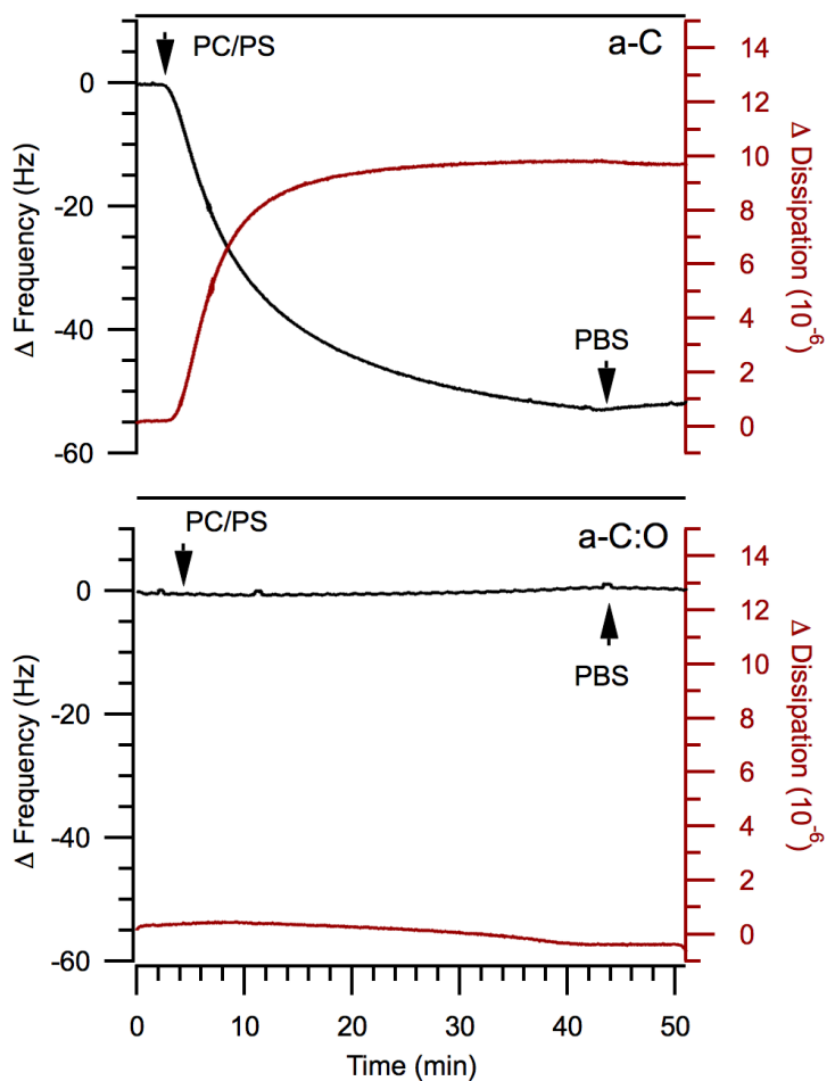

Figure 4 - QCM-D monitoring of PC/PS liposome adsorption at a-C (top) and a-C:O (bottom) surfaces. After PBS injection, the PC/PS solution $\left(0.10 \mathrm{mg} \mathrm{mL}^{-1}\right)$ was injected at $10 \mathrm{~min}$ and the interaction of PC/PS liposomes with a-C and a-C:O surfaces was monitored during 30 min; the surface was further rinsed with PBS. Values of frequency (left) and dissipation (right) are presented in the third overtone and measured in the range of 0 to $-60 \mathrm{~Hz}$ and $(0-12) \times 10^{-6}$, respectively.

QCM-D measurements in buffer solution provided further insight on the mode of liposome adsorption. Figure 4 shows representative curves obtained by monitoring changes in frequency and dissipation at a-C (top) and a-C:O (bottom) coated sensors; at time zero the crystal is stabilized in PBS, while the PC/PS liposome suspension is injected as indicated by the arrows. In the case of a-C there is a sharp decrease in frequency $(\Delta \mathrm{f}-52 \mathrm{~Hz})$ with a concomitant increase in dissipation $\left(\Delta \mathrm{D} 9.5 \times 10^{-6}\right)$, thus indicating that liposome adsorption at a-C leads to formation of a viscoelastic film with relatively large dissipation. Under our experimental conditions it was not possible to observe vesicle rupture on a-C over the course of approximately $50 \mathrm{~min}$, which would 
have been evidenced by a collapse in the dissipation value (close to 0) after the initial adsorption. In the case of a-C:O, no changes in frequency or dissipation are observed thus indicating that no adsorption takes place at oxidized surfaces. These results are in agreement with FRAP experiments and further indicate that liposome adsorption from solution occurs via formation of supported vesicular layers at graphitic a-C surfaces, whereas on oxidized surfaces liposome adsorption is completely absent.

Liposome adsorption in the presence of a di-cation. Previous work on liposome interactions at inorganic oxides and model monolayers on $\mathrm{Au}^{60}$ has shown that substrate wetting properties and surface charge can affect the outcome of liposome/solid interactions. For hydrophilic and/or charged surfaces specifically, the presence of di-cations can promote liposome adsorption and rupture. ${ }^{60,}$ 91-92 To assess the effect of di-cations in the case of graphitic and oxidised carbon surfaces exposed to natural PC/PS, $10 \mathrm{mM} \mathrm{CaCl}_{2}$ was added to the phosphate buffer while keeping the ionic strength constant at $164 \mathrm{mM}$. Figure 5a displays a comparison of the average hydrodynamic diameter of PC/PS liposomes obtained in PBS solution after a single membrane extrusion $(0.45 \mu \mathrm{m})$, in the absence and presence of $10 \mathrm{mM} \mathrm{Ca}^{2+}$. Introduction of the di-cation results in a lower hydrodynamic diameter of $128 \pm 3 \mathrm{~nm}$ (PDI 0.3) vs. $148 \pm 2 \mathrm{~nm}$ (PDI 0.4); the liposome size remains stable over time with no evidence of aggregation in suspension (Supporting Information). Stability of PC/PS in $\mathrm{Ca}^{2+}$-containing buffer is further supported by $\zeta$ potential determinations shown in Figure 5a (right). The curves indicate that replacement of $\mathrm{Na}^{+}$ counterions with $\mathrm{Ca}^{2+}$ leads to an increase in the mean $\zeta$-potential from $-84.6 \pm 0.8 \mathrm{mV}$ to $-43.5 \pm$ $1.3 \mathrm{mV}$, however this higher value remains in the accepted range for colloidal stability. The observed contraction in hydrodynamic size and the positive shift in $\zeta$-potential are consistent with proposed models of $\mathrm{Ca}^{2+} /$ phospholipid interactions. $\mathrm{Ca}^{2+}$ binds more strongly to headgroups 
compared to $\mathrm{Na}^{+}$and results in a condensing effect with consequent increase in chain packing and reduced curvature radius. ${ }^{93-94}$ Some groups have also reported liposome aggregation upon $\mathrm{Ca}^{2+}$ addition; ${ }^{95}$ however, we did not observe any evidence of aggregation, likely due to the concentration range and ionic strength conditions chosen for our experiments.

Di-cations are thought to interact with phosphate groups of both PC and PS, however it has been highlighted that PS headgroups introduce additional binding sites thanks to the presence of carboxylate groups. ${ }^{94-97}$ In the case of our PC/PS liposomes, we confirmed that the presence of PS was indeed essential for observing the above trends; Figure 5b shows the hydrodynamic size and $\zeta$-potential curves of PC-only liposomes measured under identical conditions of ionic strength and $\mathrm{pH}$, with and without $10 \mathrm{mM} \mathrm{Ca}^{2+}$ in the PBS buffer. It is clear that the lack of PS in the liposome membrane results in slightly larger vesicles whose $\zeta$-potential is not affected by the presence of $\mathrm{Ca}^{2+}$ counterions.
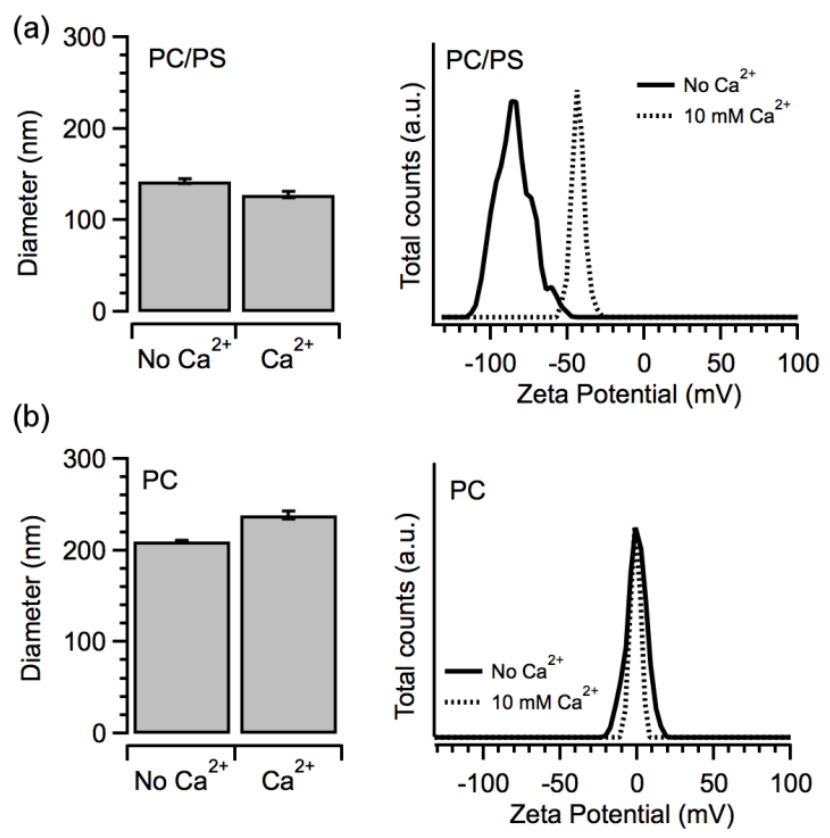

Figure 5. (a) Hydrodynamic diameter (left) and $\zeta$-potential values (right) of PC/PS liposomes in the absence (solid line) and presence (dotted line) of $10 \mathrm{mM} \mathrm{CaCl}_{2}$ in PBS. (b) Hydrodynamic diameter (left) and $\zeta$-potential values (right) of PC liposomes in the absence (solid line) and presence (dotted line) of $10 \mathrm{mM} \mathrm{CaCl}_{2}$ in PBS. The total ionic strength was kept at $1.8 \mathrm{mM}$. 
Figure 6a shows IRRAS spectra in the $\mathrm{C}-\mathrm{H}$ stretching region for a-C and a-C:O surfaces after 1 $\mathrm{h}$ incubation of PC/PS liposomes in PBS, and in PBS with $10 \mathrm{mM} \mathrm{CaCl}_{2}$ buffers; all spectra are ratioed against a pristine a-C background. Spectra of a-C surfaces exhibits the characteristic peaks of adsorbed lipid tails independently of whether the di-cation is present in solution. a-C:O surfaces, on the other hand, show a dramatic increase in $\mathrm{C}-\mathrm{H}$ absorbances upon introduction of $\mathrm{Ca}^{2+}$ in solution, indicating that di-cations clearly have a switching effect on PC/PS adsorption at the oxidised surface. A comparison of $-\mathrm{CH}_{2}$ net absorbances at a-C suggests that $\mathrm{Ca}^{2+}$ binding might also enhance lipid adsorption at this more graphitic surface ( $20 \%$ increase in intensity), however it is not possible to exclude that chain reorientation might be responsible for the observed enhancement. ${ }^{88,98}$
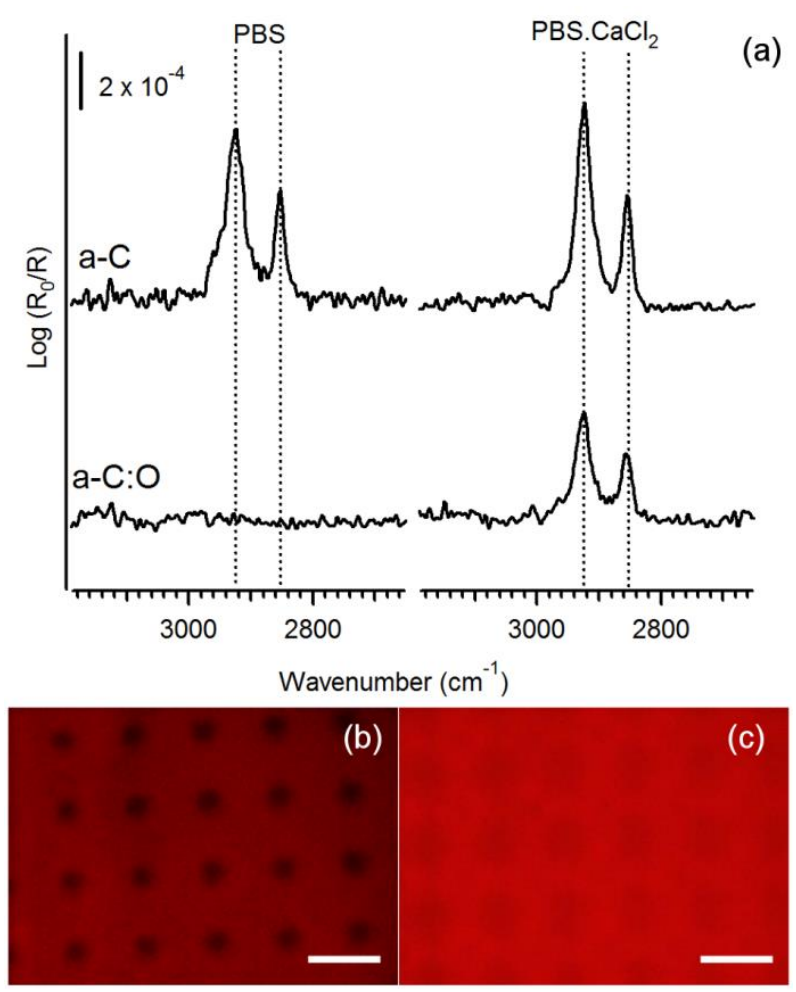

Figure 6. (a) IRRAS spectra in the region $3200-2650 \mathrm{~cm}^{-1}$ of a-C and a-C:O surfaces after $1 \mathrm{~h}$ incubation of liposomes suspended in PBS and PBS with $10 \mathrm{mM} \mathrm{CaCl} 2$ at $\mathrm{pH}$ 7.4. The position of $-\mathrm{CH}_{2}$ stretching bands is indicated with dotted lines. Fluorescence images of a-C:O patterned over the a-C surface after incubation in suspensions of fluorescently labelled PC/PS liposomes (1 $\mathrm{mM} \mathrm{PC} / \mathrm{PS}, 1 \mathrm{~h}$ ) in PBS (b) and in PBS with $10 \mathrm{mM} \mathrm{CaCl}_{2}$ (c) at $\mathrm{pH}$ 7.4; scalebar $=500 \mu \mathrm{m}$. 
Fluorescence imaging experiments carried out using PC/PS liposomes labelled with Texas Red DHPE confirmed the effect of di-cations observed via IRRAS. Carbon surfaces were oxidised via UV/ozone through a shadow mask, thus creating a-C surfaces with oxidised circular regions in a regular array (Supporting Information); these samples were then exposed to the PC/PS suspensions. Figures $6 \mathrm{~b}$ and $6 \mathrm{c}$ show fluorescence images obtained in the absence and presence, respectively, of $\mathrm{Ca}^{2+}$ in the PBS solution. In the absence of $\mathrm{Ca}^{2+}$, the emission intensity was found to be approximately $40 \%$ higher in the a-C (non-oxidised) compared to a-C:O regions, and the chemical contrast created via patterned oxidation translated into spatial control over lipid surface density. The intensity contrast was found to be negligible in the presence of $\mathrm{Ca}^{2+}$, which effectively overwhelms the substrate chemistry leading to increased adsorption over the entire surface. These results confirmed that differences in peak intensities in IRRAS reflect differences in lipid density. The introduction of $\mathrm{Ca}^{2+}$ enhances adsorption at both a-C and a-C:O surfaces effectively overcoming the chemical contrast created via patterned oxidation.

Study of liposome rupture. To investigate whether the carbon surface chemistry had an effect on liposome adsorbate structures upon vesicle rupture, we carried out AFM characterization studies at surfaces decorated with ruptured vesicles. Graphitic a-C and oxidized a-C:O surfaces (see Supporting Information) were exposed to a small volume of liposome suspension in PBS solution $(20 \mu \mathrm{L})$, then rinsed in water and imaged via AFM in air. Figure $7 \mathrm{a}$ shows the topography of a-C samples; images display adsorbates in the form of smooth "islands" that are consistent with the presence of supported lipid layers obtained after rupture. ${ }^{92,99}$ The step edge of these layers yielded an average height of $1.13 \pm 0.04 \mathrm{~nm}$, which strongly suggests that the preferred mode of adsorption involves formation of supported monolayer aggregates, in analogy with previous studies on graphite surfaces. ${ }^{100-102}$ Similar results were obtained in the case of 
samples incubated under identical conditions but in the presence of $\mathrm{Ca}^{2+}$, as shown in Figure $7 \mathrm{~b}$. The thickness of the supported layer was found to be $1.1 \pm 0.1 \mathrm{~nm}$ which again indicates formation of monolayers after rupture.

(a)

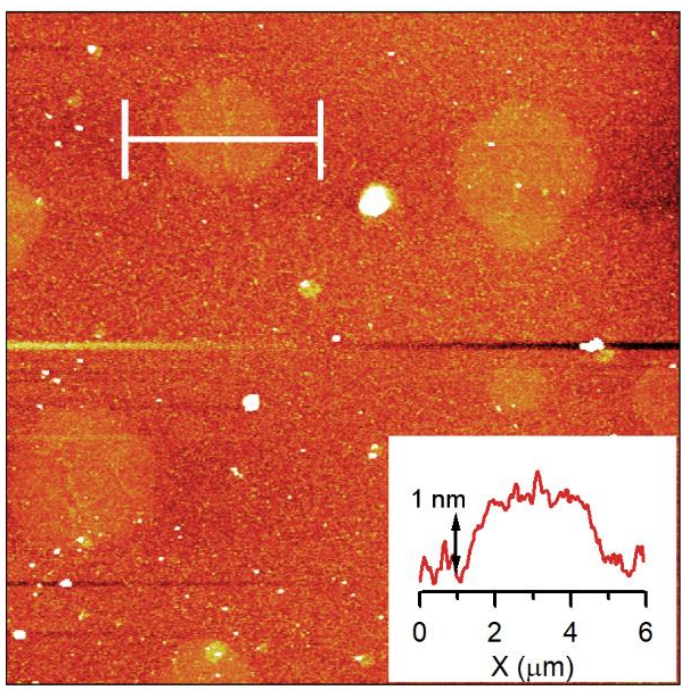

(b)

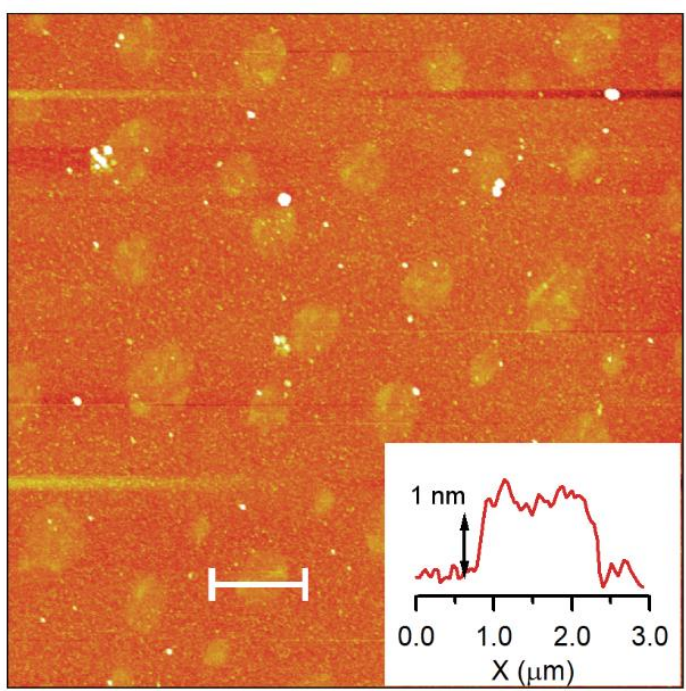

Figure 7. AFM images $\left(20 \times 20 \mu \mathrm{m}^{2}\right)$ of a-C surfaces after incubation in $20 \mu \mathrm{L}$ of $1 \mathrm{mM}$ PC/PS suspensions in (a) PBS and (b) PBS with $10 \mathrm{mM} \mathrm{CaCl}_{2}$ at $\mathrm{pH}$ 7.4. Average height profiles obtained from the regions indicated in the images are shown in the insets. The profiles show step edges of $c a .1 .1 \mathrm{~nm}$ thickness in either absence or presence of $\mathrm{Ca}^{2+}$. 

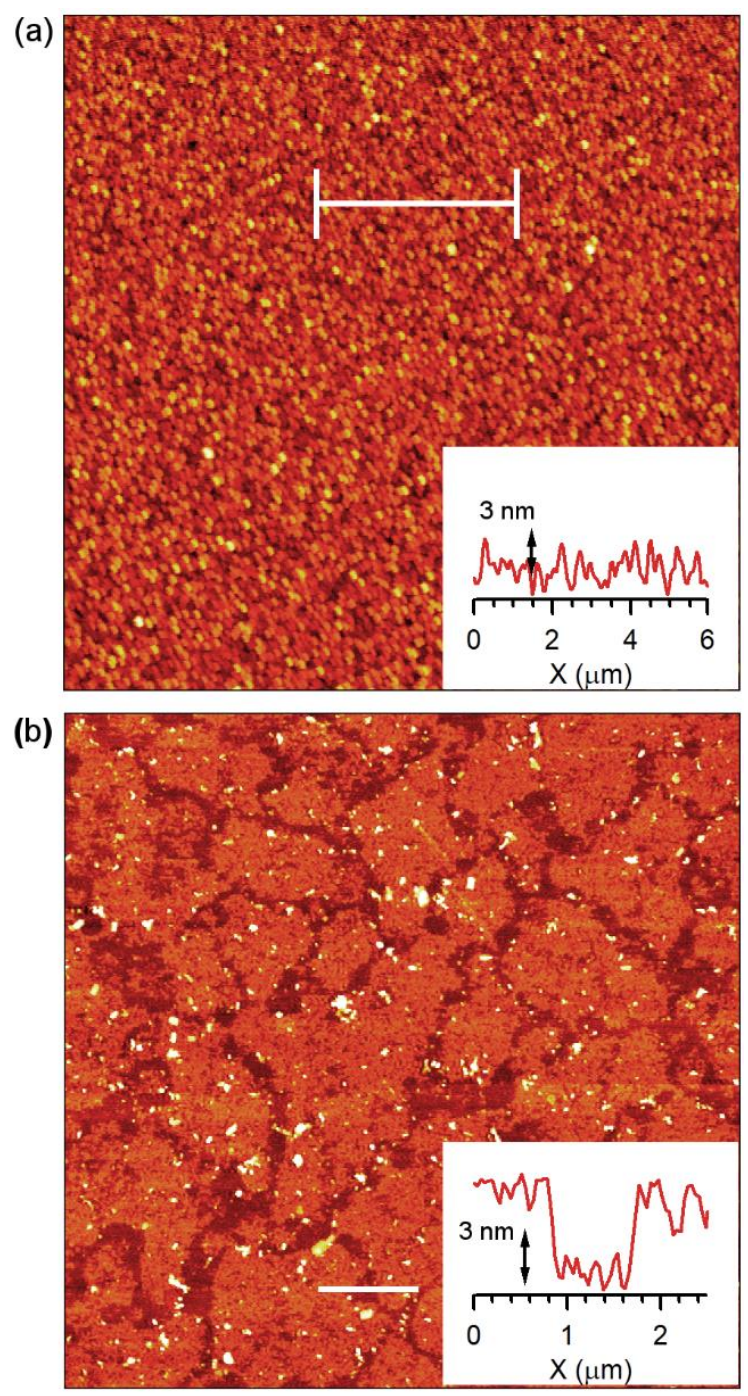

Figure 8. AFM images $\left(20 \times 20 \mu \mathrm{m}^{2}\right)$ of a-C:O surfaces after incubation in $20 \mu \mathrm{L}$ of $1 \mathrm{mM} \mathrm{PC} / \mathrm{PS}$ suspensions in (a) PBS and (b) PBS with $10 \mathrm{mM} \mathrm{CaCl}_{2}$ at $\mathrm{pH}$ 7.4. Average (a) and individual (b) height profiles obtained from the region indicated in the image are shown in the insets. The images show no evidence of adsorption in PBS, while a discontinuous layer of thickness $\mathrm{ca}$. 4.4 $\mathrm{nm}$ is obtained in the presence of $\mathrm{Ca}^{2+}$.

Equivalent imaging experiments on oxidised a-C:O surfaces are shown in Figures 8a and 8b. In the absence of $\mathrm{Ca}^{2+}$ (Figure 8a), the incubation process did not yield any adsorbates, in agreement with IRRAS and fluorescence images. The introduction of the di-cation resulted in the formation of a defective supported layer (Figure 8b) whose average height was found to be $4.4 \pm$ $0.7 \mathrm{~nm}$, in agreement with AFM thickness determinations of PC supported bilayers. ${ }^{100,103}$ These 
results indicate that the introduction of a di-cation can be used to promote liposome adsorption at oxidized carbon surfaces, however the resulting supported lipids consist of bilayers and differ from the monolayer adsorbates formed via vesicle rupture at graphitic surfaces.

\section{Discussion}

The results herein presented show that there are marked differences in the amount and structure of lipid adsorbates on carbon surfaces with different surface chemistry. A combination of spectroscopic, nanogravimetric and fluorescence studies indicates that adsorption at graphitic surfaces occurs predominantly in the form of supported intact vesicles; however, under conditions that promote rupture, adsorbates appear to consist of supported lipid monolayers, based on the experimentally determined height profiles (Figures 7 and 8). All experiments showed that carbon oxidation results in liposome rejection when compared with graphitic surfaces, such as a-C.

The introduction of a di-cation $\left(\mathrm{Ca}^{2+}\right)$ in the buffer was found to promote liposome adsorption, with the most remarkable changes observed in the case of oxidised surfaces. Interestingly, after vesicle rupture, the adsorbate thickness is much larger than that observed on graphitic surfaces and consistent with the presence of supported lipid bilayer (Figures 7 and 8). Therefore, our results indicate that the specific carbon surface termination/modification can dictate both density and type of lipid adsorption either in the presence or absence of the di-cation, a result that has important implications for applications of carbon coatings or nanocarbons as biomaterials, membrane supports and sensing surfaces. In the following paragraphs, the effect of (i) carbon surface chemistry and wettability and (ii) buffer ionic valence, on the outcome of liposome/carbon interactions is discussed. 
Carbon Surface Chemistry and Wettability. Several studies have reported on the interaction of lipid aggregates with model solid surfaces, such as $\mathrm{SiO}_{2},{ }^{51} \mathrm{TiO}_{2},{ }^{60}$ and mica ${ }^{92}$ and showed that wettability is critical in determining the outcome of liposome adsorption at the solid/liquid interface. $^{60,86,104-106}$ It has been observed that at hydrophobic surfaces liposomes adsorb preferentially as supported vesicle layers (SVL) or supported lipid monolayers (SLM), whereas at hydrophilic surfaces a supported lipid bilayer (SLB) can form. This behaviour was reviewed by Tero et al. ${ }^{60}$ who attributed the liposome structure at hydrophilic surfaces to the higher density of $-\mathrm{OH}$ groups, which correlates to the increase of hydration repulsion forces between the stable layer of water molecules attached to the phospholipid head groups and the water bound to the solid substrate.

Research on the interaction of liposomes with carbon coatings and surfaces is relatively sparse and the role of carbon surface chemistry and wettability on the structure of adsorbed liposomes is poorly understood. Among carbon materials, lipid adsorption on few-layer graphene has received attention, primarily for the fabrication of graphene-based electronic sensors. ${ }^{59,} 107-109$ Experiments with synthetic lipids show that graphene displays similar trends to those observed for oxide materials. Pristine graphene yields monolayers ${ }^{107}$ or inverted bilayers ${ }^{109}$ when subject to lipid deposition via solvent-assisted or dip-pen lithography methods, thus indicating a preference for adsorption of hydrophobic tails at the graphene interface. In situ vesicle fusion experiments by Tabaei et al. ${ }^{107}$ also suggest preferential monolayer formation on pristine graphene, although vesicle rupture events were not observed. Studies on graphene oxide (GO), ${ }^{50,107,109}$ on the other hand, typically show evidence of preferred interaction between GO and lipid polar heads, resulting in formation of bilayers, bicells or supported vesicle layers. As in the case of oxide model surfaces, the adsorbate structure was proposed to be regulated by surface wettability; 
hydrophobic graphene preferentially adsorbed intact vesicles (SVL) or SLM while hydrophilic substrates tended to form a SLB at the interface. ${ }^{108,110}$

In our studies, a-C surfaces with WCA of $35.25 \pm 2.86^{\circ}$ incubated in PC/PS liposomes revealed the presence of SVL at the interface in QCM-D and FRAP experiments in solution. Interestingly, after incubation in PC/PS suspension in PBS, oxidised carbon (a-C:O), an extremely hydrophilic surface with a WCA $<5^{\circ}$, no liposome adsorption was observed. The complete absence of liposome adsorption at macroscopic surfaces and at physiological $\mathrm{pH}$ is rare, or perhaps underreported, suggesting that for these surfaces control over surface wettability is not a sufficient condition to promote liposome fusion and adsorption. ${ }^{60,73}$

In addition to a substantial decrease in wettability, oxidation results in a change in the density of ionisable groups at the surface, which is also known to play a critical role on liposome/surface interactions and adsorbate structures. Experimental values on amorphous carbon surfaces showed that at neutral $\mathrm{pH}, \mathrm{a}-\mathrm{C}$ and a-C:O surfaces display a $\mathrm{SZP}$ of $-51.3 \pm 2.4 \mathrm{mV}$ and -61.5 $\pm 3.6 \mathrm{mV}$, respectively. ${ }^{72}$ The additional negative electrostatic charge arising from acid groups in a-C:O surfaces suggests that repulsive contributions from surface charges might inhibit liposome rupture. ${ }^{111}$ Repulsive interactions have been proposed to explain reduced liposome adsorption on other types of carbon materials. ${ }^{111-113}$ For instance, Wang et al. ${ }^{112}$ reported on the interaction of DOPC liposomes with nanodiamonds and proposed that electrostatic repulsions between nanodiamond surface groups and liposome headgroups are responsible for reduced adsorption at pH 9. Frost et al. ${ }^{111}$ observed complete repulsion between PC/PS liposome suspensions and graphene oxide surfaces, with an oxygen content of $20 \%$ and a surface $\zeta$-potential of $-56 \pm 1.1$ $\mathrm{mV}$ at non-physiological $\mathrm{pH}(\mathrm{pH}=4)$. In the case of a-C:O the repulsive effects appears to be strong even at neutral $\mathrm{pH}$ thus offering a viable method for the creation of liposome-resistant 
coatings/surfaces and for achieving spatial control of lipids on carbon surfaces and electrodes under physiological conditions.

Influence of Mono-/Di- Cation. Results from our experiments indicate that buffer ionic valence must be taken into consideration when interpreting interfacial behaviour. Literature suggests that the introduction of a di-cation favours bilayer adsorption at solid surfaces. ${ }^{73}, 114-115$ Previous reports in the literature ${ }^{56,73,91,96,99,114-120}$ have focused on the effects of buffer composition, i.e. charge, ionic strength and ion nature, on the interaction between liposome and solid surface. The role of the cation is complex and has received significant attention, as it can affect adsorption through changes in liposome stability, liposome-surface interactions and liposome-liposome interactions at the solid interface. ${ }^{91}$ The positive shift in SZP in Figure 5a indicates strong association of $\mathrm{Ca}^{+2}$ to the lipid headgroups, as expected based on experimentally determined association constants for $\mathrm{Ca}^{+2}$ at phosphate groups obtained at PC supported films. ${ }^{121}$ However, under our experimental conditions, there is no evidence of vesicle destabilization, thus indicating that changes in liposome adsorption observed at a-C/a-C:O surfaces are primarily determined by effects of the dication on liposome-carbon, and possibly liposome-liposome interactions.

In our experiments the effect of $\mathrm{Ca}^{2+}$ in PC/PS liposome adsorption was observed for both graphitic and oxidised carbon surfaces. The graphitic surface displays a slight enhancement of PC/PS adsorption when $\mathrm{Ca}^{2+}$ is added to the buffer, however it is on the oxidised surface that the introduction of the dication has a dramatic impact. Zwitterionic liposomes can interact with solid surfaces through both positively charged choline groups or negatively charged phosphate groups. Seantier and Kasemo ${ }^{91}$ have proposed that binding of the dication to the phosphate groups might screen more effectively the negative pole of zwitterionic lipid heads, thus increasing attractive interactions with negatively charged surfaces. Given the negative SZP of amorphous carbon 
surfaces and the spectroscopic evidence of abundant carboxylate groups at neutral $\mathrm{pH}$ on a-C:O, it is expected that $\mathrm{Ca}^{2+}$ ions at the solid/liquid interface can bridge surface carboxylates and phosphate head groups at the liposome surface. ${ }^{91,} 99,120$ Increased attractive interactions are expected to promote adsorption of intact vesicles and lead to deformation at the carbon interface, thus facilitating the rupture process. $\mathrm{Ca}^{+2}$ binding is also known to contribute to a decrease in the strength of liposome-liposome repulsive interactions; this additional effect further promotes rupture of adsorbed liposomes at the carbon surface. ${ }^{118,122}$

\section{Conclusions}

In this work, the interaction of PC/PS liposomes with amorphous carbon surfaces was studied with regards to buffer composition and carbon surface chemistry and wettability. The amount and mode of liposome adsorption at a-C and a-C:O surfaces were investigated by using a combination of spectroscopic, nanogravimetric and microscopic techniques. IRRAS experiments on carbon surfaces after exposure to PC/PS liposome suspensions in PBS showed liposome adsorption exclusively at a-C surfaces for all $\mathrm{pH}$ investigated; QCM-D and FRAP measurements revealed that PC/PS liposomes adsorb at a-C surfaces as supported intact vesicles. The lack of liposome adsorption at the oxidised surface is attributed to the significantly higher hydrophilicity and density of charged groups, which results in an increase of electrostatic repulsion between liposomes and a-C:O surfaces.

The introduction of the dication $\mathrm{Ca}^{2+}$ in the buffer solution led to PC/PS liposome adsorption at $\mathrm{a}-\mathrm{C}: \mathrm{O}$ and a slightly increased adsorption at a-C surfaces. Fluorescence results were in good agreement with IRRAS measurements, indicating a lower a-C:O/a-C fluoresence intensity ratio when the dication was added to the phosphate buffer. Finally, AFM measurements gave insights 
about the structure of adsorbates: under conditions that promote liposome rupture, PC/PS liposomes adsorb as a monolayer on a-C, while for $\mathrm{a}-\mathrm{C}$ : $\mathrm{O}$ the adsorption of a bilayer is only observed when the dication is added.

Herein we demonstrate that tailoring of the carbon surface chemistry can be leveraged to control surface density of PC/PS liposome adsorbates and adsorbate structure. These results have implications on applications of amorphous carbon films in the biomedical field, where the mode and amount of model lipid aggregate adsorption at the interface might be critical in determining the bioresponse of carbon-based biodevices. Equally, these results are relevant for applications of carbon-based sensors and electrodes that require membrane immobilization e.g. as enzyme or bio-receptor supports.

\section{Acknowledgements}

This publication has emanated from research conducted with the financial support of Science

Foundation Ireland under Grant No. 12/IP/1273. MDA gratefully acknowledges support by Enterprise Ireland Grant Number CF/2012/2634. The authors would like to thank Mr. G. McManus for Fluorescence Microscope assistance and Mr. S. Mills for AFM training and support. JMV is grateful to Ms. M. Browne for her intellectual input.

\section{References}

1. Buddy D. Ratner; Allan S. Hoffman; Frederick J. Schoen; Jack E. Lemons, Biomaterials Science. 2 ed.; Elsevier Academic Press: London, 2004.

2. Gott, V. L.; Alejo, D. E.; Cameron, D. E., Mechanical Heart Valves: 50 Years of Evolution. Ann. Thorac. Surg. 2003, 76, S2230-9.

3. Grill, A., Diamond-Like Carbon Coatings as Biocompatible Materials - an Overview. Diamond Relat. Mater. 2003, 12, 166-170. 
4. Dearnaley, G.; Arps, J. H., Biomedical Applications of Diamond-Like Carbon (Dlc) Coatings: A Review. Surf. Coat. Technol. 2005, 200, 2518-2524.

5. $\quad$ Roy, R. K.; Lee, K. R., Biomedical Applications of Diamond-Like Carbon Coatings: A Review. J Biomed Mater Res B Appl Biomater 2007, 83, 72-84.

6. Sydow-Plum, G.; Tabrizian, M., Review of Stent Coating Strategies: Clinical Insights. Mater. Sci. Technol. 2008, 24, 1127-1143.

7. $\quad$ Lockett, M. R.; Weibel, S. C.; Phillips, M. F.; Shortreed, M. R.; Sun, B.; Corn, R. M.; Hamers, R. J.; Cerrina, F.; Smith, L. M., Carbon-on-Metal Films for Surface Plasmon Resonance Detection of DNA Arrays. J. Am. Chem. Soc. 2008, 130, 8611-8613.

8. Sun, B.; Colavita, P. E.; Kim, H.; Lockett, M.; Marcus, M. S.; Smith, L. M.; Hamers, R. J., Covalent Photochemical Functionalization of Amorphous Carbon Thin Films for Integrated Real-Time Biosensing. Langmuir 2006, 22, 9598-9605.

9. Zen, F.; Karanikolas, V. D.; Behan, J. A.; Andersson, J.; Ciapetti, G.; Bradley, A. L.; Colavita, P. E., Nanoplasmonic Sensing at the Carbon-Bio Interface: Study of Protein Adsorption at Graphitic and Hydrogenated Carbon Surfaces. Langmuir 2017, 33, 4198-4206.

10. Liang, F.; Chen, B., A Review on Biomedical Applications of Single-Walled Carbon Nanotubes. Curr. Med. Chem. 2010, 17, 10-24.

11. Krishna, V.; Stevens, N.; Koopman, B.; Moudgil, B., Optical Heating and Rapid Transformation of Functionalized Fullerenes. Nat Nano 2010, 5, 330-334.

12. Chen, M.; Pierstorff, E. D.; Lam, R.; Li, S.-Y.; Huang, H.; Osawa, E.; Ho, D., Nanodiamond-Mediated Delivery of Water-Insoluble Therapeutics. ACS Nano 2009, 3, 20162022.

13. Faklaris, O.; Joshi, V.; Irinopoulou, T.; Tauc, P.; Sennour, M.; Girard, H.; Gesset, C.; Arnault, J.-C.; Thorel, A.; Boudou, J.-P., et al., Photoluminescent Diamond Nanoparticles for Cell Labeling: Study of the Uptake Mechanism in Mammalian Cells. ACS Nano 2009, 3, 39553962.

14. Fang, Y.; Gu, D.; Zou, Y.; Wu, Z.; Li, F.; Che, R.; Deng, Y.; Tu, B.; Zhao, D., A LowConcentration Hydrothermal Synthesis of Biocompatible Ordered Mesoporous Carbon Nanospheres with Tunable and Uniform Size. Angew. Chem. Int. Ed. 2010, 49, 7987-7991.

15. Duffy, P.; Magno, L. M.; Yadav, R. B.; Roberts, S. K.; Ward, A. D.; Botchway, S. W.; Colavita, P. E.; Quinn, S. J., Incandescent Porous Carbon Microspheres to Light up Cells: Solution Phenomena and Cellular Uptake. J. Mater. Chem. 2012, 22, 432-439.

16. Robertson, J., Diamond-Like Amorphous Carbon. Mater. Sci. Eng., R 2002, 37, 129-281. 
17. Gutensohn, K.; Beythien, C.; Bau, J.; Fenner, T.; Grewe, P.; Koester, R.; Padmanaban, K.; Kuehnl, P., In Vitro Analyses of Diamond-Like Carbon Coated Stents: Reduction of Metal Ion Release, Platelet Activation, and Thrombogenicity. Thromb. Res. 2000, 99, 577-585.

18. Hauert, R., A Review of Modified Dlc Coatings for Biological Applications. Diamond Relat. Mater. 2003, 12, 583-589.

19. Ma, W. J.; Ruys, A. J.; Mason, R. S.; Martin, P. J.; Bendavid, A.; Liu, Z.; Ionescu, M.; Zreiqat, H., Dlc Coatings: Effects of Physical and Chemical Properties on Biological Response. Biomaterials 2007, 28, 1620-1628.

20. Ohgoe, Y.; Hirakuri, K. K.; Saitoh, H.; Nakahigashi, T.; Ohtake, N.; Hirata, A.; Kanda, K.; Hiratsuka, M.; Fukui, Y., Classification of Dlc Films in Terms of Biological Response. Surf. Coat. Technol. 2012, 207, 350-354.

21. Lackner, M. J.; Waldhauser, W., Diamond and Diamond-Like Carbon Coated Surfaces as Biomaterials. Berg- Huettenmaenn. Monatsh. 2010, 155, 528-533.

22. Love, C. A.; Cook, R. B.; Harvey, T. J.; Dearnley, P. A.; Wood, R. J. K., Diamond Like Carbon Coatings for Potential Application in Biological Implants—a Review. Tribol. Int. 2013, 63, 141-150.

23. Chai, F.; Mathis, N.; Blanchemain, N.; Meunier, C.; Hildebrand, H. F., Osteoblast Interaction with Dlc-Coated Si Substrates. Acta biomaterialia 2008, 4, 1369-81.

24. Bociaga, D.; Kaminska, M.; Sobczyk-Guzenda, A.; Jastrzebski, K.; Swiatek, L.; Olejnik, A., Surface Properties and Biological Behaviour of Si-Dlc Coatings Fabricated by a Multi-Target Dc-Rf Magnetron Sputtering Method for Medical Applications. Diamond Relat. Mater. 2016, 67, 41-50.

25. Bociąga, D.; Jakubowski, W.; Komorowski, P.; Sobczyk-Guzenda, A.; Jędrzejczak, A.; Batory, D.; Olejnik, A., Surface Characterization and Biological Evaluation of SilverIncorporated Dlc Coatings Fabricated by Hybrid Rf Pacvd/Ms Method. Mater. Sci. Eng., C 2016, $63,462-474$.

26. Kasemo, B., Biological Surface Science. Curr. Opin. Solid State Mater. Sci. 1998, 3, 451-459.

27. Schwartz, Z.; Boyan, B. D., Underlying Mechanisms at the Bone-Biomaterial Interface. J. Cell. Biochem. 1994, 56, 340-7.

28. Thevenot, P.; Hu, W.; Tang, L., Surface Chemistry Influences Implant Biocompatibility. Curr. Top. Med. Chem. 2008, 8, 270-280.

29. Reimhult, E.; Zäch, M.; Höök, F.; Kasemo, B., A Multitechnique Study of Liposome Adsorption on Au and Lipid Bilayer Formation on Sio2. Langmuir 2006, 22, 3313-3319. 
30. Parhami, F.; Garfinkel, A.; Demer, L. L., Role of Lipids in Osteoporosis. Arterioscler., Thromb., Vasc. Biol. 2000, 20, 2346-2348.

31. Zen, F.; Angione, M. D.; Behan, J. A.; Cullen, R. J.; Duff, T.; Vasconcelos, J. M.; Scanlan, E. M.; Colavita, P. E., Modulation of Protein Fouling and Interfacial Properties at Carbon Surfaces Via Immobilization of Glycans Using Aryldiazonium Chemistry. Sci. Rep. 2016, 6, 24840.

32. Kratz, A.; Ferraro, M.; Sluss, P. M.; Lewandrowski, K. B., Normal Reference Laboratory Values. N. Engl. J. Med. 2004, 351, 1548-1563.

33. Quehenberger, O.; Armando, A. M.; Brown, A. H.; Milne, S. B.; Myers, D. S.; Merrill, A. H.; Bandyopadhyay, S.; Jones, K. N.; Kelly, S.; Shaner, R. L., et al., Lipidomics Reveals a Remarkable Diversity of Lipids in Human Plasma. J. Lipid Res. 2010, 51, 3299-3305.

34. Baier, R. E.; Dutton, R. C., Initial Events in Interactions of Blood with a Foreign Surface. J. Biomed. Mater. Res. 1969, 3, 191-206.

35. Griesser, H. J.; Kingshott, P.; McArthur, S. L.; McLean, K. M.; Kinsel, G. R.; Timmons, R. B., Surface-Maldi Mass Spectrometry in Biomaterials Research. Biomaterials 2004, 25, 48614875.

36. Hellstrand, E.; Lynch, I.; Andersson, A.; Drakenberg, T.; Dahlbäck, B.; Dawson, K. A.; Linse, S.; Cedervall, T., Complete High-Density Lipoproteins in Nanoparticle Corona. FEBS J. 2009, 276, 3372-3381.

37. Yeagle, P. L., Introduction to Lipid Bilayers. In The Structure of Biological Membranes, Third Edition, CRC Press: 2011; pp 1-6.

38. Lombard, J., Once Upon a Time the Cell Membranes: 175 Years of Cell Boundary Research. Biol Direct 2014, 9, 32.

39. Hussain, M. M., A Proposed Model for the Assembly of Chylomicrons. Atherosclerosis 2000, $148,1-15$.

40. Kurt W. Miller; Donald M. Smalls, Surface-to-Core and Interparticle Equilibrium Distributions of Triglyceride-Rich Lipoprotein Lipids. J. Biol. Chem. 1983, 258, 13772-13784.

41. Daniel, M., Boundary Cartilage Lubrication: Review of Current Concepts. Wien Med Wochenschr 2014, 164, 88-94.

42. Verberne, G.; Schroeder, A.; Halperin, G.; Barenholz, Y.; Etsion, I., Liposomes as Potential Biolubricant Additives for Wear Reduction in Human Synovial Joints. Wear 2010, 268, 1037-1042.

43. Hills, B. A.; Crawford, R. W., Normal and Prosthetic Synovial Joints Are Lubricated by Surface-Active Phospholipid. J. Arthroplasty 2003, 18, 499-505. 
44. Pawlak, Z.; Urbaniak, W.; Hagner-Derengowska, M.; Hagner, W., The Probable Explanation for the Low Friction of Natural Joints. Cell Biochem. Biophys. 2015, 71, 1615-21.

45. Yang, W.; Cui, F. Z.; Qing, X., Behavior of Phosphatidylcholine Adsorption on Cnx Coated Ptfe Films. Curr. Appl. Phys. 2006, 6, 827-832.

46. Sessa, G.; Weissmann, G., Phospholipid Spherules (Liposomes) as a Model for Biological Membranes. J. Lipid Res. 1968, 9, 310-8.

47. Akbarzadeh, A.; Rezaei-Sadabady, R.; Davaran, S.; Joo, S.; Zarghami, N.; Hanifehpour, Y.; Samiei, M.; Kouhi, M.; Nejati-Koshki, K., Liposome: Classification, Preparation, and Applications. Nanoscale Research Letters 2013, 8, 1-9.

48. McConnell, H. M.; Watts, T. H.; Weis, R. M.; Brian, A. A., Supported Planar Membranes in Studies of Cell-Cell Recognition in the Immune System. Biochim. Biophys. Acta 1986, 864, 95-106.

49. Towns, E. N.; Parikh, A. N.; Land, D. P., Influence of Vesicle Size and Aqueous Solvent on Intact Phospholipid Vesicle Adsorption on Oxidized Gold Monitored Using Attenuated Total Reflectance Fourier Transform Infrared Spectroscopy. J. Phys. Chem. C 2015, 119, 2412-2418.

50. Okamoto, Y.; Tsuzuki, K.; Iwasa, S.; Ishikawa, R.; Sandhu, A.; Tero, R., Fabrication of Supported Lipid Bilayer on Graphene Oxide. J. Phys. Conf. 2012, 352, 012017.

51. Cho, N.-J.; Frank, C. W.; Kasemo, B.; Hook, F., Quartz Crystal Microbalance with Dissipation Monitoring of Supported Lipid Bilayers on Various Substrates. Nat. Protocols 2010, 5, 1096-1106.

52. Scarano, S.; Mascini, M.; Turner, A. P. F.; Minunni, M., Surface Plasmon Resonance Imaging for Affinity-Based Biosensors. Biosensors and Bioelectronics 2010, 25, 957-966.

53. Limaj, O.; Etezadi, D.; Wittenberg, N. J.; Rodrigo, D.; Yoo, D.; Oh, S. H.; Altug, H., Infrared Plasmonic Biosensor for Real-Time and Label-Free Monitoring of Lipid Membranes. Nano Lett. 2016, 16, 1502-8.

54. Castellana, E. T.; Cremer, P. S., Solid Supported Lipid Bilayers: From Biophysical Studies to Sensor Design. Surf. Sci. Rep. 2006, 61, 429-444.

55. Saeui, C. T.; Mathew, M. P.; Liu, L.; Urias, E.; Yarema, K. J., Cell Surface and Membrane Engineering: Emerging Technologies and Applications. J Funct Biomater 2015, 6, 454-85.

56. Sovago, M.; Wurpel, G. W. H.; Smits, M.; Müller, M.; Bonn, M., Calcium-Induced Phospholipid Ordering Depends on Surface Pressure. J. Am. Chem. Soc. 2007, 129, 1107911084.

57. Cui, F. Z.; Qing, X. L.; Li, D. J.; Zhao, J., Biomedical Investigations on Cnx Coating. Surf. Coat. Technol. 2005, 200, 1009-1013. 
58. Marco Diociaiuti; Agnese Molinari; Irene Ruspantini; Maria Cristina Gaudiano; Rodolfo Ippoliti; Eugenio Lendaro; Federico Bordi; Pietro Chistolini; Giuseppe Arancia, P-Glycoprotein Inserted in Planar Lipid Bilayers Formed by Liposomes Opened on Amorphous Carbon and Langmuir-Blodgett Monolayer. Biochim. Biophys. Acta 2002, 1559, 21-31.

59. Tsuzuki, K.; Okamoto, Y.; Iwasa, S.; Ishikawa, R.; Sandhu, A.; Tero, R., Reduced Graphene Oxide as the Support for Lipid Bilayer Membrane. J. Phys. Conf. 2012, 352, 012016.

60. Tero, R., Substrate Effects on the Formation Process, Structure and Physicochemical Properties of Supported Lipid Bilayers. Materials 2012, 5, 2658-2680.

61. Morales-Lara, F.; Pérez-Mendoza, M. J.; Altmajer-Vaz, D.; García-Román, M.; Melguizo, M.; López-Garzón, F. J.; Domingo-García, M., Functionalization of Multiwall Carbon Nanotubes by Ozone at Basic $\mathrm{Ph}$. Comparison with Oxygen Plasma and Ozone in Gas Phase. $J$. Phys. Chem. C 2013, 117, 11647-11655.

62. Simmons, J. M.; Nichols, B. M.; Baker, S. E.; Marcus, M. S.; Castellini, O. M.; Lee, C. S.; Hamers, R. J.; Eriksson, M. A., Effect of Ozone Oxidation on Single-Walled Carbon Nanotubes. J. Phys. Chem. B 2006, 110, 7113-7118.

63. Mochalin, V. N.; Shenderova, O.; Ho, D.; Gogotsi, Y., The Properties and Applications of Nanodiamonds. Nat Nano 2012, 7, 11-23.

64. May, P. W.; Regan, E. M.; Taylor, A.; Uney, J.; Dick, A. D.; McGeehan, J., Spatially Controlling Neuronal Adhesion on Cvd Diamond. Diamond Relat. Mater. 2012, 23, 100-104.

65. Nistor, P. A.; May, P. W.; Tamagnini, F.; Randall, A. D.; Caldwell, M. A., Long-Term Culture of Pluripotent Stem-Cell-Derived Human Neurons on Diamond - a Substrate for Neurodegeneration Research and Therapy. Biomaterials 2015, 61, 139-149.

66. Regan, E. M.; Taylor, A.; Uney, J. B.; Dick, A. D.; May, P. W.; McGeehan, J., Spatially Controlling Neuronal Adhesion and Inflammatory Reactions on Implantable Diamond. IEEE J. Em. Sel. Top. C. 2011, 1, 557-565.

67. Morrissey, J. H. Morrissey Laboratory Protocol for Preparing Phospholipid Vesicles (Suv) by Sonication. (accessed 04.10.2016).

68. Liu, Z.; Brady, A.; Young, A.; Rasimick, B.; Chen, K.; Zhou, C.; Kallenbach, N. R., Length Effects in Antimicrobial Peptides of the (Rw)N Series. Antimicrob. Agents Chemother. 2007, 51, 597-603.

69. Silva-Lopez, E. I.; Edens, L. E.; Barden, A. O.; Keller, D. J.; Brozik, J. A., Conditions for Liposome Adsorption and Bilayer Formation on Bsa Passivated Solid Supports. Chem. Phys. Lipids 2014, 183, 91-9.

70. Cullen, R. J.; Jayasundara, D. R.; Soldi, L.; Cheng, J. J.; Dufaure, G.; Colavita, P. E., Spontaneous Grafting of Nitrophenyl Groups on Amorphous Carbon Thin Films: A StructureReactivity Investigation. Chem. Mater. 2012, 24, 1031-1040. 
71. Cullen, R. J.; Jayasundara, D. R.; Baker, R. J.; O' Connell, G.; Donnelly, T.; Ballantine, K. E.; Lunney, J. G.; Colavita, P. E., Laser-Driven Rapid Functionalization of Carbon Surfaces and Its Application to the Fabrication of Fluorinated Adsorbers. RSC Advances 2016, 6, 8292482932.

72. Vasconcelos, J. M.; Zen, F.; Stamatin, S. N.; Behan, J. A.; Colavita, P. E., Determination of Surface Z-Potential and Isoelectric Point of Carbon Surfaces Using Tracer Particle Suspensions. Surf. Interface Anal. 2017, 49, 781-787.

73. Cha, T.; Guo, A.; Zhu, X. Y., Formation of Supported Phospholipid Bilayers on Molecular Surfaces: Role of Surface Charge Density and Electrostatic Interaction. Biophys. J. 2006, 90, 1270-1274.

74. Moreno-Castilla, C.; Ferro-Garcia, M. A.; Joly, J. P.; Bautista-Toledo, I.; CarrascoMarin, F.; Rivera-Utrilla, J., Activated Carbon Surface Modifications by Nitric Acid, Hydrogen Peroxide, and Ammonium Peroxydisulfate Treatments. Langmuir 1995, 11, 4386-4392.

75. Socrates, G., Infrared and Raman Characteristic Group Frequencies: Tables and Charts. John Wiley \& Sons: 2001.

76. Metz, K. M.; Colavita, P. E.; Tse, K. Y.; Hamers, R. J., Nanotextured Gold Coatings on Carbon Nanofiber Scaffolds as Ultrahigh Surface-Area Electrodes. J. Power Sources 2012, 198, 393-401.

77. Jacquot, A.; Francius, G.; Razafitianamaharavo, A.; Dehghani, F.; Tamayol, A.; Linder, M.; Arab-Tehrany, E., Morphological and Physical Analysis of Natural Phospholipids-Based Biomembranes. PLoS One 2014, 9, e107435.

78. Tefas, L. R.; Muntean, D.; Vlase, L.; Porfire, A. S.; Achim, M.; Tomuta, I., QuercetinLoaded Liposomes: Formulation Optimization through a D-Optimal Experimental Design. Farmacia 2015, 63.

79. Silva Malheiros, P.; Micheletto, Y. M. S.; Silveira, N. P. d.; Brandelli, A., Development and Characterization of Phosphatidylcholine Nanovesicles Containing the Antimicrobial Peptide Nisin. Food Res. Int. 2010, 43, 1198-1203.

80. Yandrapati, R. K. Effect of Lipid Composition on the Physical Properties of Liposomes: A Light Scattering Study. 2012.

81. Sułkowski, W. W.; Pentak, D.; Nowak, K.; Sułkowska, A., The Influence of Temperature, Cholesterol Content and Ph on Liposome Stability. J. Mol. Struct. 2005, 744-747, 737-747.

82. Moncelli, M. R.; Becucci, L.; Guidelli, R., The Intrinsic Pka Values for Phosphatidylcholine, Phosphatidylethanolamine, and Phosphatidylserine in Monolayers Deposited on Mercury Electrodes. Biophys. J. 1994, 66, 1969-1980. 
83. Tsui, F. C.; Ojcius, D. M.; Hubbell, W. L., The Intrinsic Pka Values for Phosphatidylserine and Phosphatidylethanolamine in Phosphatidylcholine Host Bilayers. Biophys. J. 1986, 49, 459-468.

84. Bangham, A. D.; Papahadjopoulos, D., Biophysical Properties of Phospholipids. I. Interaction of Phosphatidylserine Monolayers with Metal Ions. Biochim. Biophys. Acta 1966, $126,181-184$.

85. Jiang, C.; Gamarnik, A.; Tripp, C. P., Identification of Lipid Aggregate Structures on Tio2 Surface Using Headgroup Ir Bands. J. Phys. Chem. B 2005, 109, 4539-4544.

86. Er, Y.; Prestidge, C. A.; Fornasiero, D., Attenuated Total Reflectance Infrared Studies of Liposome Adsorption at the Solid-Liquid Interface. Colloids Surf. B 2004, 36, 147-153.

87. Hernandez, M. R.; Towns, E. N.; Ng, T. C.; Walsh, B. C.; Osibanjo, R.; Parikh, A. N.; Land, D. P., Use of Attenuated Total Reflectance Fourier Transform Infrared Spectroscopy to Monitor the Development of Lipid Aggregate Structures. Appl. Opt. 2012, 51, 2842-6.

88. Mashaghi, A.; Mashaghi, S.; Reviakine, I.; Heeren, R. M.; Sandoghdar, V.; Bonn, M., Label-Free Characterization of Biomembranes: From Structure to Dynamics. Chem. Soc. Rev. 2014, 43, 887-900.

89. Hull, M. C.; Cambrea, L. R.; Hovis, J. S., Infrared Spectroscopy of Fluid Lipid Bilayers. Anal. Chem. 2005, 77, 6096-9.

90. Lewis, R. N.; McElhaney, R. N.; Pohle, W.; Mantsch, H. H., Components of the Carbonyl Stretching Band in the Infrared Spectra of Hydrated 1,2-Diacylglycerolipid Bilayers: A Reevaluation. Biophys. J. 1994, 67, 2367-2375.

91. Seantier, B.; Kasemo, B., Influence of Mono- and Divalent Ions on the Formation of Supported Phospholipid Bilayers Via Vesicle Adsorption. Langmuir 2009, 25, 5767-5772.

92. Richter, R. P.; Brisson, A. R., Following the Formation of Supported Lipid Bilayers on Mica: A Study Combining Afm, Qcm-D, and Ellipsometry. Biophys. J. 2005, 88, 3422-3433.

93. Pedersen, U. R.; Leidy, C.; Westh, P.; Peters, G. H., The Effect of Calcium on the Properties of Charged Phospholipid Bilayers. Biochim. Biophys. Acta, Biomembr. 2006, 1758, 573-582.

94. Sinn, C. G.; Antonietti, M.; Dimova, R., Binding of Calcium to PhosphatidylcholinePhosphatidylserine Membranes. Colloids Surf. A 2006, 282, 410-419.

95. Melcrová, A.; Pokorna, S.; Pullanchery, S.; Kohagen, M.; Jurkiewicz, P.; Hof, M.; Jungwirth, P.; Cremer, P. S.; Cwiklik, L., The Complex Nature of Calcium Cation Interactions with Phospholipid Bilayers. Sci. Rep. 2016, 6, 38035. 
96. Boettcher, J. M.; Davis-Harrison, R. L.; Clay, M. C.; Nieuwkoop, A. J.; Ohkubo, Y. Z.; Tajkhorshid, E.; Morrissey, J. H.; Rienstra, C. M., Atomic View of Calcium-Induced Clustering of Phosphatidylserine in Mixed Lipid Bilayers. Biochemistry 2011, 50, 2264-2273.

97. Martín-Molina, A.; Rodríguez-Beas, C.; Faraudo, J., Effect of Calcium and Magnesium on Phosphatidylserine Membranes: Experiments and All-Atomic Simulations. Biophys. J. 2012, 102, 2095-2103.

98. Tolstoy, V. P.; Chernyshova, I.; Skryshevsky, V. A., Handbook of Infrared Spectroscopy of Ultrathin Films. Wiley: 2003.

99. Richter, R.; Mukhopadhyay, A.; Brisson, A., Pathways of Lipid Vesicle Deposition on Solid Surfaces: A Combined Qcm-D and Afm Study. Biophys. J. 2003, 85, 3035-3047.

100. Nagle, J. F.; Tristram-Nagle, S., Lipid Bilayer Structure. Curr. Opin. Struct. Biol. 2000, $10,474-480$.

101. Kiselyova, O. I.; Guryev, O. L.; Krivosheev, A. V.; Usanov, S. A.; Yaminsky, I. V., Atomic Force Microscopy Studies of Langmuir-Blodgett Films of Cytochrome P450scc: Hemeprotein Aggregation States and Interaction with Lipids. Langmuir 1999, 15, 1353-1359.

102. Diculescu, V. C.; Chiorcea-Paquim, A.-M.; Tugulea, L.; Vivan, M.; Oliveira-Brett, A.M., Interaction of Imatinib with Liposomes: Voltammetric and Afm Characterization. Bioelectrochemistry 2009, 74, 278-288.

103. Egawa, H.; Furusawa, K., Liposome Adhesion on Mica Surface Studied by Atomic Force Microscopy. Langmuir 1999, 15, 1660-1666.

104. Alexandrova, L.; Karakashev, S. I.; Grigorov, L.; Phan, C. M.; Smoukov, S. K., Wetting Properties of Phospholipid Dispersion on Tunable Hydrophobic Sio2-Glass Plates. Adv. Colloid Interface Sci. 2015, 220, 1-7.

105. Jurak, M.; Chibowski, E., Wettability and Topography of Phospholipid Dppc Multilayers Deposited by Spin-Coating on Glass, Silicon, and Mica Slides. Langmuir 2007, 23, 1015610163.

106. Isono, T.; Tanaka, H.; Ogino, T., Effect of Chemical Modification of the Substrate Surface on Supported Lipid Bilayer Formation. e-J. Surf. Sci. Nanotechnol. 2007, 5, 99-102.

107. Tabaei, S. R.; Ng, W. B.; Cho, S.-J.; Cho, N.-J., Controlling the Formation of Phospholipid Monolayer, Bilayer, and Intact Vesicle Layer on Graphene. ACS Appl. Mater. Interfaces 2016, 8, 11875-11880.

108. Ang, P. K.; Jaiswal, M.; Lim, C. H.; Wang, Y.; Sankaran, J.; Li, A.; Lim, C. T.; Wohland, T.; Barbaros, O.; Loh, K. P., A Bioelectronic Platform Using a Graphene-Lipid Bilayer Interface. ACS Nano 2010, 4, 7387-94. 
109. Willems, N.; Urtizberea, A.; Verre, A. F.; Iliut, M.; Lelimousin, M.; Hirtz, M.; Vijayaraghavan, A.; Sansom, M. S. P., Biomimetic Phospholipid Membrane Organization on Graphene and Graphene Oxide Surfaces: A Molecular Dynamics Simulation Study. ACS Nano 2017, 11, 1613-1625.

110. Li, W.; Chung, J. K.; Lee, Y. K.; Groves, J. T., Graphene-Templated Supported Lipid Bilayer Nanochannels. Nano Lett. 2016, 16, 5022-5026.

111. Frost, R.; Jönsson, G. E.; Chakarov, D.; Svedhem, S.; Kasemo, B., Graphene Oxide and Lipid Membranes: Interactions and Nanocomposite Structures. Nano Lett. 2012, 12, 3356-3362.

112. Wang, F.; Liu, J., Nanodiamond Decorated Liposomes as Highly Biocompatible Delivery Vehicles and a Comparison with Carbon Nanotubes and Graphene Oxide. Nanoscale 2013, 5 , 12375-82.

113. Liu, J., Interfacing Zwitterionic Liposomes with Inorganic Nanomaterials: Surface Forces, Membrane Integrity, and Applications. Langmuir 2016, 32, 4393-4404.

114. Rossetti, F. F.; Bally, M.; Michel, R.; Textor, M.; Reviakine, I., Interactions between Titanium Dioxide and Phosphatidyl Serine-Containing Liposomes: Formation and Patterning of Supported Phospholipid Bilayers on the Surface of a Medically Relevant Material. Langmuir 2005, 21, 6443-6450.

115. Reviakine, I.; Brisson, A., Formation of Supported Phospholipid Bilayers from Unilamellar Vesicles Investigated by Atomic Force Microscopy. Langmuir 2000, 16, 1806-1815.

116. Böckmann, R. A.; Grubmüller, H., Multistep Binding of Divalent Cations to Phospholipid Bilayers: A Molecular Dynamics Study. Angew. Chem. Int. Ed. 2004, 43, 10211024.

117. Puu, G.; Gustafson, I., Planar Lipid Bilayers on Solid Supports from Liposomes - Factors of Importance for Kinetics and Stability. Biochim. Biophys. Acta, Biomembr. 1997, 1327, 149161.

118. Hardy, G. J.; Nayak, R.; Zauscher, S., Model Cell Membranes: Techniques to Form Complex Biomimetic Supported Lipid Bilayers Via Vesicle Fusion. Curr. Opin. Colloid Interface Sci. 2013, 18, 448-458.

119. Fernanda F. Rossetti; Marcus Textor; Ilya Reviakine, Asymmetric Distribution of Phosphatidyl Serine in Supported Phospholipid Bilayers on Titanium Dioxide. Langmuir 2006, 22, 3467-3473.

120. Walker, G. M., Biotechnological Implications of the Interactions between Magnesium and Calcium. Magnes Res 1999, 12, 303-9.

121. Marra, J.; Israelachvili, J., Direct Measurements of Forces between Phosphatidylcholine and Phosphatidylethanolamine Bilayers in Aqueous Electrolyte Solutions. Biochemistry 1985, 24, 4608-4618. 
122. Cremer, P. S.; Boxer, S. G., Formation and Spreading of Lipid Bilayers on Planar Glass Supports. J. Phys. Chem. B 1999, 103, 2554-2559. 